Taksonomia 29

\title{
Tomasz Pisula
}

Politechnika Rzeszowska

e-mail: tpisula@prz.edu.pl

\section{ANALIZA PORÓWNAWCZA ROZWOJU SEKTORA BANKOWO-KREDYTOWEGO W KRAJACH UE Z WYKORZYSTANIEM METOD TAKSONOMICZNYCH \\ COMPARATIVE ANALYSIS OF THE DEVELOPMENT OF THE BANKING AND CREDIT SECTOR IN THE EU COUNTRIES USING THE TAXONOMIC METHODS}

DOI: 10.15611/pn.2017.469.14

JEL Classification: C38, G21, G23

Streszczenie: Sektor bankowo-kredytowy w sytuacji pojawiających się zawirowań i kryzysów finansowych jest szczególnie wrażliwy na ryzyko występowania licznych niekorzystnych zjawisk. Celem artykułu jest uzyskanie odpowiedzi na pytania dotyczące stopnia podobieństwa rozwoju sektora bankowo-kredytowego w Polsce w porównaniu z innymi krajami UE oraz zbadanie, które kraje charakteryzują się najlepszym poziomem jego rozwoju. $Z$ wykorzystaniem metod taksonomicznych wyodrębniono skupienia krajów podobnych pod względem poziomu rozwoju sektora bankowo-kredytowego i przeanalizowano zmiany w strukturze skupień krajów podobnych, które nastąpiły w dobie kryzysu finansowego (rok 2014) w stosunku do okresu przed kryzysem (rok 2008). Wyznaczono ranking krajów UE ze względu na poziom rozwoju sektora bankowo-kredytowego w obu porównywanych okresach. Zbadano, które kraje są najlepsze w rankingu rozwoju, a także porównano pozycję Polski w stosunku do krajów najlepszych oraz pozostałych krajów Europy Środkowo-Wschodniej.

Słowa kluczowe: sektor bankowo-kredytowy, analiza skupień, klasyfikacja spektralna, uogólniona miara odległości GDM, ranking.

Summary: Banking and credit sector in a situation of emerging turbulence and financial crises is particularly sensitive to the risk of numerous adverse events. This article aims to answer the key questions about the degree of similarity in the development of banking and credit sector in Poland compared to other European Union countries and to examine which countries in the EU are characterized by the highest level of their development. With the use of taxonomic methods there have been distinguished the clusters of countries which are similar in terms of the level of development of the banking and credit sector and the changes in the structure of clusters of similar countries that followed the financial crisis (2014) as compared to pre-crisis (2008) have been analysed. The ranking of the EU countries on grounds of the level of development of the banking and credit sector in both comparable periods has been determined.

Keywords: banking and credit sector, cluster analysis, spectral clustering, generalized distance measure GDM, ranking. 


\section{Wstęp}

Jednym z podstawowych rodzajów działalności banków oraz innych instytucji kredytowych (w świetle dyrektywy UE) jest działalność związana z udzielaniem i obsługą kredytów. Jest to jedno z podstawowych źródeł dochodów dla całego sektora bankowo-kredytowego, choć wiążące się ze znacznym ryzykiem. Stabilny oraz właściwy rozwój tego sektora jest podstawą zachowania stabilności dla całego systemu finansowego państwa. Sektor bankowo-kredytowy, w sytuacji pojawiających się zawirowań, szoków i kryzysów finansowych (z którymi od kilku lat mamy do czynienia), jest szczególnie wrażliwy na ryzyko występowania licznych niekorzystnych zjawisk. Dlatego bardzo ważna i uzasadniona jest analiza poziomu rozwoju oraz diagnoza wpływu ewentualnych niekorzystnych zjawisk na stabilność sektora bankowego w krajach Unii Europejskiej.

Badania i analizy dotyczące rozwoju sektora bankowego w Polsce w porównaniu z innymi krajami oraz wpływu globalnego kryzysu na pozycję polskiego sektora bankowego w Unii Europejskiej były prowadzone już wcześniej w polskiej literaturze przedmiotu. Tej problematyce badawczej poświęcone są m.in. prace: [Stefański 2010; Lepczyński, Penczar 2014]. W wymienionych pracach przedstawiono analizy wskaźnikowe dotyczące pozycji ekonomicznej oraz siły finansowej sektorów bankowych Polski oraz nowych krajów członkowskich UE-12. Przeprowadzono także analizy (w tym badania taksonomiczne) badające zmiany w pozycji polskiego sektora bankowego na europejskim rynku depozytowo-kredytowym w latach 2009-2012.

Głównym celem przeprowadzonych badań, których wyniki są przedstawione w niniejszym artykule, jest uzyskanie odpowiedzi na następujące kluczowe pytania: jakie czynniki najbardziej wpływają na rozwój sektora bankowo-kredytowego, w jakich krajach występują znaczne podobieństwa w poziomie rozwoju sektora bankowo-kredytowego, czy w dobie kryzysu finansowego (rok 2014) nastąpiły ewentualne zmiany w strukturze skupień krajów podobnych w stosunku do okresu przed kryzysem (rok 2008ㅁ), które z krajów charakteryzują się najlepszym poziomem rozwoju sektora bankowo-kredytowego w badanych okresach oraz jak Polska wypada w rankingu w porównaniu z innymi krajami UE oraz krajami Europy Środkowo-Wschodniej?

W celu odpowiedzi na tak postawione pytania przeprowadzono badania taksonomiczne podobieństwa rozwoju badanego sektora oraz sporządzono ranking krajów Unii Europejskiej z wykorzystaniem wzorcowych metod porządkowania liniowego.

${ }^{1}$ Za umowną datę rozpoczęcia kryzysu finansowego przyjęto rok 2009, czyli rok bezpośrednio po upadku banku inwestycyjnego Lehman Brothers (wrzesień 2008). Jednakże w analizach dotyczących przyczyn obecnego kryzysu finansowego za datę jego rozpoczęcia przyjmuje się czasami nawet rok 2007. 


\section{Charakterystyka zmiennych diagnostycznych wykorzystanych w badaniu}

W badaniach rozwoju sektora bankowo-kredytowego krajów UE jako zmienne diagnostyczne wytypowano różne czynniki opisujących kluczowe aspekty jego rozwoju oraz charakteryzujące poziom jego stabilności finansowej. Pierwotnie wzięto pod uwagę 25 różnych wskaźników charakteryzujących m.in.: dostępność społeczeństwa do usług bankowych, wskaźniki zatrudnienia w sektorze bankowym, wskaźniki określające stopień koncentracji sektora bankowego, wskaźniki określające poziom aktywów instytucji kredytowych, poziom udzielonych kredytów i posiadanych depozytów, wskaźniki określające jakość portfeli kredytowych oraz poziom kapitałów własnych banków wykorzystywanych do zabezpieczania się przed skutkami ryzyka kredytowego, stopę zwrotu z aktywów ROA, stopę zwrotu z kapitałów własnych ROE itp.

Tabela 1. Podstawowe statystyki opisowe dla zmiennych diagnostycznych w 2014 i 2008 roku

\begin{tabular}{|c|c|c|c|c|c|c|}
\hline \multirow{2}{*}{ Zmienna } & \multirow{2}{*}{ Opis zmiennej } & \multicolumn{5}{|c|}{ Statystyki opisowe (2014 | 2008) } \\
\hline & & średnia & $\min$. & $\max$. & $\begin{array}{l}\text { odch. } \\
\text { stand. }\end{array}$ & $\begin{array}{c}\text { wsp. zm. } \\
V_{s}(\%)\end{array}$ \\
\hline $\mathrm{X}_{1}$ & $\begin{array}{l}\text { Depozyty banków } \\
\text { komercyjnych jako \% PKB }\end{array}$ & $\begin{array}{l}66,7 \\
62,6\end{array}$ & $\begin{array}{l}28,1 \\
23,0\end{array}$ & $\begin{array}{l}161,5 \\
148,0\end{array}$ & $\begin{array}{l}32,4 \\
34,9\end{array}$ & $\begin{array}{l}48,6 \\
55,7\end{array}$ \\
\hline$X_{2}$ & $\begin{array}{l}\text { Kredyty banków komercyjnych } \\
\text { jako \% PKB }\end{array}$ & $\begin{array}{l}77,9 \\
87,6 \\
\end{array}$ & $\begin{array}{l}21,5 \\
23,7\end{array}$ & $\begin{array}{l}184,9 \\
199,5\end{array}$ & $\begin{array}{l}40,6 \\
48,6 \\
\end{array}$ & $\begin{array}{l}52,1 \\
55,4\end{array}$ \\
\hline $\mathrm{X}_{3}$ & $\begin{array}{l}\text { Odsetek kredytów zagrożonych } \\
(\%)\end{array}$ & $\begin{array}{l}9,9 \\
2,8\end{array}$ & $\begin{array}{l}0,2 \\
0,4\end{array}$ & $\begin{array}{r}44,9 \\
6,3\end{array}$ & $\begin{array}{r}10,2 \\
1,6\end{array}$ & $\begin{array}{r}103,5 \\
55,8\end{array}$ \\
\hline $\mathrm{X}_{4}$ & $\begin{array}{l}\text { Oddziały instytucji } \\
\text { kredytowych / } 100 \text { tys. } \\
\text { ludności }\end{array}$ & $\begin{array}{l}33,2 \\
42,0\end{array}$ & $\begin{array}{r}9,3 \\
19,2\end{array}$ & $\begin{array}{r}71,7 \\
118,9\end{array}$ & $\begin{array}{l}16,9 \\
24,4\end{array}$ & $\begin{array}{l}50,9 \\
58,1\end{array}$ \\
\hline $\mathrm{X}_{5}$ & $\begin{array}{l}\text { Pracownicy instytucji } \\
\text { kredytowych / } 1 \text { oddział }\end{array}$ & $\begin{array}{l}24,0 \\
22,3\end{array}$ & $\begin{array}{l}6,3 \\
5,6\end{array}$ & $\begin{array}{l}119,0 \\
118,3\end{array}$ & $\begin{array}{l}21,6 \\
21,2\end{array}$ & $\begin{array}{l}90,1 \\
95,1\end{array}$ \\
\hline$X_{6}$ & $\begin{array}{l}\text { Średnia wartość aktywów } \\
\text { bankowych / } 1 \text { bank (mld euro) }\end{array}$ & $\begin{array}{l}5,3 \\
4,4 \\
\end{array}$ & $\begin{array}{l}0,3 \\
0,3\end{array}$ & $\begin{array}{l}24,9 \\
22,0\end{array}$ & $\begin{array}{l}5,8 \\
4,8 \\
\end{array}$ & $\begin{array}{l}109,8 \\
108,4\end{array}$ \\
\hline $\mathrm{X}_{7}$ & $\begin{array}{l}\text { Udział wartości kredytów } \\
\text { bankowych danego kraju } \\
\text { w ogólnej wartości kredytów } \\
\text { dla UE }(\%)\end{array}$ & $\begin{array}{l}3,6 \\
3,6\end{array}$ & $\begin{array}{r}0,1 \\
0,05\end{array}$ & $\begin{array}{l}19,1 \\
20,4\end{array}$ & $\begin{array}{l}5,9 \\
5,7\end{array}$ & $\begin{array}{l}164,0 \\
158,6\end{array}$ \\
\hline $\mathrm{X}_{8}$ & $\begin{array}{l}\text { Kapitały własne i rezerwy } \\
\text { banków / aktywów (\%) }\end{array}$ & $\begin{array}{r}10,8 \\
6,7\end{array}$ & $\begin{array}{l}5,0 \\
3,2\end{array}$ & $\begin{array}{l}22,8 \\
13,5\end{array}$ & $\begin{array}{l}4,7 \\
2,3\end{array}$ & $\begin{array}{l}43,2 \\
34,6\end{array}$ \\
\hline $\mathrm{X}_{9}$ & $\begin{array}{l}\text { Herfindahl index dla } \\
\text { koncentracji aktywów sektora } \\
\text { bankowego }(\%)\end{array}$ & $\begin{array}{l}11,4 \\
11,2\end{array}$ & $\begin{array}{l}3,0 \\
1,9\end{array}$ & $\begin{array}{l}33,1 \\
31,6\end{array}$ & $\begin{array}{l}7,1 \\
7,4\end{array}$ & $\begin{array}{l}62,0 \\
65,9\end{array}$ \\
\hline
\end{tabular}

Źródło: opracowanie własne. 
Przy wyborze zmiennych kierowano się głównie ich merytoryczną przydatnością w badaniu, a w dalszej kolejności dostępnością danych statystycznych oraz starano się wytypować takie czynniki, które znacznie różnicują badane kraje oraz są stosunkowo słabo ze sobą skorelowane. Ponadto starano się wytypować tylko takie czynniki, które nie są zmiennymi zakłócającymi dla procedury wyodrębniania skupień krajów podobnych. Badanie, w jakim stopniu zmienne diagnostyczne mogą zakłócać tworzone skupienia, przeprowadzono z wykorzystaniem heurystycznej procedury identyfikacji zmiennych zakłócających HINoV (zob. [Walesiak 2016, s. 66] dostępnej w pakiecie R (funkcja HINoV, biblioteka ClusterSim).

Dane statystyczne wykorzystane $w$ analizach pochodziły $\mathrm{z}$ internetowych baz danych: Statistical Data Warehouse (SDW) - Europejskiego Banku Centralnego (ECB), Financial Soundness Indicators (FSI) - Międzynarodowego Funduszu Walutowego (IMF) oraz statystyk dostępnych w opracowaniu [European Banking Federation 2015]. Tabela 1 przedstawia obliczone wartości podstawowych statystyk opisowych dla wytypowanych ostatecznie do badania 9 zmiennych diagnostycznych.

\section{Taksonomiczna ocena podobieństwa rozwoju sektora bankowo-kredytowego w krajach UE}

W celu zbadania podobieństw w rozwoju sektora bankowo-kredytowego w krajach Unii Europejskiej wyodrębniono skupienia krajów podobnych pod względem wartości wybranych czynników diagnostycznych z zastosowaniem metod analizy skupień. Możliwości wykorzystania metod taksonomicznych w grupowaniu obiektów są dobrze znane i bardzo szeroko opisywane w literaturze (zob. np. [Grabiński, Wydymus, Zeliaś 1989]). Jako metodę badawczą zastosowano metodę klasyfikacji spektralnej, której dokładne omówienie można znaleźć w literaturze (zob. np. [Walesiak 2016, s. 73-74]). Wybrane zmienne diagnostyczne były poddawane unormowaniu wartości z wykorzystaniem procedury standaryzacji. Do wyznaczenia tzw. macierzy podobieństw obiektów (affinity matrix) postaci:

$$
A_{i k}= \begin{cases}0 & \text { dla } i=k \\ e^{\left(-\sigma d_{i k}\right)} & \text { dla } i \neq k\end{cases}
$$

wykorzystano uogólnioną miarę odległości $d_{i k}=G D M 1_{i k}$ dla danych metrycznych, zaproponowaną przez Walesiaka (por. [2016, s. 43]). Macierz ta została poddana dekompozycji, w wyniku której wyznaczano jej wartości własne oraz odpowiadające im wektory własne. Następnie uporządkowano wektory własne według malejących wartości własnych. Pierwsze $s$ ( $s$ - ustalona liczba skupień) wektorów własnych po odpowiedniej normalizacji stanowiło macierz danych wejściowych. Dla tak wyznaczonej macierzy danych zastosowano metodę $k$-średnich i wyznaczono ostateczne skupienia obiektów. Do obliczeń zastosowano procedurę analizy spektralnej Speccl dostępną w pakiecie R (biblioteka Clustersim). Procedura Speccl wyznacza także optymalną wartość parametru $\sigma$ dla macierzy podobieństw, korzystając z odpowiedniego algorytmu zaproponowanego w pracy [Walesiak, Dudek 2009]. 
Bardzo istotnym problemem w klasyfikacji spektralnej jest dobór optymalnej liczby skupień $s$. Wykorzystuje się tutaj dwa możliwe podejścia: pierwsze to wybór optymalnej liczby skupień z zastosowaniem metody Girolamiego (zob. [2002]), drugie podejście opiera się na wykorzystaniu odpowiednich indeksów ocen jakości klasyfikacji. W analizie spektralnej podobieństwa krajów UE pod względem rozwoju sektora bankowo-kredytowego zastosowano to drugie podejście. Wykorzystano 8 indeksów dostępnych w bibliotece Clustersim. Indeksy te umożliwiają określenie takiej liczby skupień, która w sposób najbardziej optymalny klasyfikuje badane obiekty (dla których to klasyfikacji wartość indeksów przyjmuje najczęściej wartość maksymalną lub minimalną). Szczegółowe wzory na obliczenie wartości tych indeksów można znaleźć w pracy [Walesiak 2016, s. 71]. Przy wyznaczaniu optymalnej liczby skupień dla danych z lat 2014 i 2008 przyjęto zakres jej zmienności od 4 do 8 skupień, a obliczenia przeprowadzono z wykorzystaniem odpowiednich procedur biblioteki Clustersim. Wyznaczone wartości indeksów oraz optymalne liczby skupień dla metody klasyfikacji spektralnej w obu badanych okresach przedstawia tabela 2 .

Tabela 2. Indeksy jakości klasyfikacji dla liczby skupień w metodzie klasyfikacji spektralnej w latach 2014 i 2008

\begin{tabular}{|c|c|c|c|c|c|c|c|c|c|c|}
\hline \multirow[t]{2}{*}{ Indeks } & \multicolumn{5}{|c|}{2014} & \multicolumn{5}{|c|}{2008} \\
\hline & $\mathrm{k}=4$ & $\mathrm{k}=5$ & $\mathrm{k}=6$ & $\mathrm{k}=7$ & $\mathrm{k}=8$ & $\mathrm{k}=4$ & $\mathrm{k}=5$ & $\mathrm{k}=6$ & $\mathrm{k}=7$ & $\mathrm{k}=8$ \\
\hline $\begin{array}{l}\text { „Krzanowski-Lai” } \\
\max .\{\mathrm{KL}\}\end{array}$ & 0,70 & $3,33^{*}$ & 0,24 & 1,61 & 1,98 & 0,42 & $4,68^{*}$ & 0,98 & 3,51 & 0,48 \\
\hline $\begin{array}{l}\text { „Davies-Bouldin” } \\
\min .\{\mathrm{DB}\}\end{array}$ & 1,60 & 1,29 & 1,59 & 1,36 & $1,18^{*}$ & 1,57 & 1,26 & $1,17^{*}$ & 1,22 & 1,39 \\
\hline $\begin{array}{l}\text { „Rousseeuw” } \\
\text { Sylwetkowy } \\
\text { (Silhouette) max. }\{S\}\end{array}$ & 0,29 & $0,35^{*}$ & 0,21 & 0,21 & 0,24 & 0,19 & $0,41^{*}$ & 0,40 & 0,39 & 0,27 \\
\hline $\begin{array}{l}\text { „Tibshirani, Walther, } \\
\text { Hastie” (Gap) } \\
\text { min. }\{k\} \text { dla } \\
\text { Diffu }>=0\end{array}$ & $-0,09$ & $0,14^{*}$ & $-0,08$ & $-0,005$ & 0,13 & $-0,13$ & $0,13^{*}$ & 0,04 & 0,36 & 0,14 \\
\hline $\begin{array}{l}\text { „Hartigan” } \\
\text { min. }\{\mathrm{k}\} \text { dla } \mathrm{H}<=10\end{array}$ & $6,31^{*}$ & $-0,36$ & 7,97 & 3,46 & 1,70 & 10,72 & $3,07^{*}$ & 3,28 & 2,35 & $-3,63$ \\
\hline $\begin{array}{l}\text { „Celiński-Harabasz” } \\
\max .\{\mathrm{G} 1\}\end{array}$ & 5,78 & $6,43^{*}$ & 4,38 & 5,01 & 5,18 & 3,99 & $6,57^{*}$ & 6,23 & 6,27 & 5,42 \\
\hline $\begin{array}{l}\text { „Baker-Hubert” } \\
\max .\{\mathrm{G} 2\}\end{array}$ & 0,60 & $0,75^{*}$ & 0,52 & 0,68 & 0,61 & 0,42 & 0,77 & 0,78 & $0,80^{*}$ & 0,71 \\
\hline $\begin{array}{l}\text { "Hubert-Levin" } \\
\text { min. }\{\mathrm{G} 3\}\end{array}$ & 0,28 & $0,26^{*}$ & 0,30 & 0,41 & 0,38 & 0,36 & $0,33^{*}$ & 0,39 & 0,35 & 0,42 \\
\hline
\end{tabular}

*Optymalna wartość indeksu dla ustalonej liczby skupień.

Źródło: opracowanie własne na podstawie obliczeń z wykorzystaniem pakietu R i biblioteki Clustersim. 
Analizując wartości wyznaczonych indeksów jakości klasyfikacji, można zauważyć, że optymalną liczbą skupień dla obu badanych okresów będzie $s=5$ skupień (aż 6 z 8 indeksów wskazywało ją jako najlepszą). Dlatego w dalszej analizie przyjęto, że kraje zostaną pogrupowane w 5 skupieniach.

Na podstawie danych z 2014 roku, obejmujących 9 wybranych wskaźników charakteryzujących poziom rozwoju sektora bankowo-kredytowego w krajach Unii Europejskiej, otrzymano następujące skupienia krajów podobnych (obliczona optymalna wartość parametru sigma dla metody klasyfikacji spektralnej wynosiła $\sigma=93,2$ ).

Skupienie I: tworzą 3 kraje (Estonia, Finlandia i Litwa). Są to kraje które charakteryzują się bardzo dużą koncentracją sektora bankowego w kilku wiodących bankach. Wartości wskaźnika Herfindahla ponad dwukrotnie przekraczają średnią ogólną (w Finlandii wskaźnik monopolizacji sektora bankowego wynosił w 2014 roku ponad 33\%). Ponadto są to kraje mające stosunkowo niewielką liczbę oddziałów instytucji kredytowych na 100 tys. ludności oraz posiadające niewielki udział wartości udzielonych kredytów bankowych w stosunku do wartości kredytów dla wszystkich krajów Unii Europejskiej.

Skupienie II: tworzy 7 krajów (Belgia, Dania, Holandia, Luksemburg, Malta, Szwecja i Wielka Brytania). Są to kraje charakteryzujące się głównie dużą liczbą pracowników zatrudnionych w sektorze bankowym na jeden oddział instytucji kredytowej (średnia tego wskaźnika w skupieniu prawie 2 razy przewyższa średnią grupową). Ponadto są to w większości kraje, w których wartość zdeponowanych depozytów bankowych przekracza wartość PKB kraju (średnia tego wskaźnika w skupieniu 1,5 raza przewyższa średnią ogólną).

Skupienie III: tworzy kolejne 6 krajów (Bułgaria, Cypr, Grecja, Hiszpania, Portugalia i Włochy). Są to kraje charakteryzujące się bardzo dużym odsetkiem tzw. złych kredytów bankowych (kredytów zagrożonych). Średnia wartość tego wskaźnik w skupieniu 2,3 razy przewyższa średnią ogólną. Cypr i Grecja to kraje, gdzie odsetek złych kredytów jest ogromny (odpowiednio 45\% i 34\%). Ponadto są to kraje posiadające stosunkowo duży odsetek płynnych kapitałów własnych posiadanych przez banki na zabezpieczenie ryzyka kredytowego (średnia w skupieniu 1,3 razy przewyższa średnią ogólną) oraz w krajach tych wartość udzielonych kredytów znacznie przewyższa wartość PKB (średnia w skupieniu 1,4 razy przewyższa średnią ogólną); charakteryzują się one też dużą liczbą oddziałów instytucji kredytowych przypadających na 100 tys. ludności (iloraz średniej w skupieniu w stosunku do ogólnej 1,6).

Skupienie IV: tworzą tylko 2 kraje (Francja i Niemcy). Są to kraje charakteryzujące się bardzo dużym udziałem wartości udzielonych kredytów bankowych w stosunku do wartości kredytów dla wszystkich krajów Unii Europejskiej (udział łączny tych krajów to po $19 \%$ wartości kredytów całej Unii - iloraz średnich ponad 5,3). Ponadto jest to osiągane przy bardzo niewielkich wartościach wskaźnika koncentracji Herfindahla (średnio w skupieniu tylko 4,4\% - iloraz w stosunku do średniej ogólnej tylko 0,4). 
Skupienie V: jest najliczniejsze i tworzy je pozostałe 10 krajów (Austria, Chorwacja, Czechy, Irlandia, Łotwa, Polska, Rumunia, Słowacja, Słowenia i Węgry). Są to kraje charakteryzujące się tym, że nie mają żadnej dominującej zmiennej decydującej o wyznaczeniu tego skupienia. Są to kraje tzw. przeciętne, dla których wartości wszystkich wskaźników albo oscylują wokół średnich ogólnych, albo są znacznie poniżej tych wartości. Najniższe wartości ilorazu średnich są dla średniej wartości aktywów bankowych przypadającej na 1 bank $(0,32)$ oraz dla udziału wartości kredytów w ogólnej wartości kredytów dla wszystkich krajów Unii $(0,18)$.

Podobnie uzyskano skupienia krajów podobnych pod względem poziomu rozwoju sektora bankowo-kredytowego w 2008 roku. W tym przypadku obliczona optymalna wartość parametru sigma dla metody klasyfikacji spektralnej wynosiła $\sigma=86,1$. Rysunek 1 przedstawia strukturę skupień dla badanych krajów w obu okresach. Obliczone bardzo wysokie wartości miar podobieństwa klasyfikacji Nowaka $(0,83)$ i skorygowanego indeksu Randa $(0,81)$ (zob. [Walesiak 2016, s. 82]) wskazują na to, że struktura skupień krajów podobnych w przeprowadzonym badaniu w roku 2014 w stosunku do 2008 nie uległa zmianie. Można zaobserwować tylko nieliczne migracje dla kilku krajów pomiędzy skupieniami.
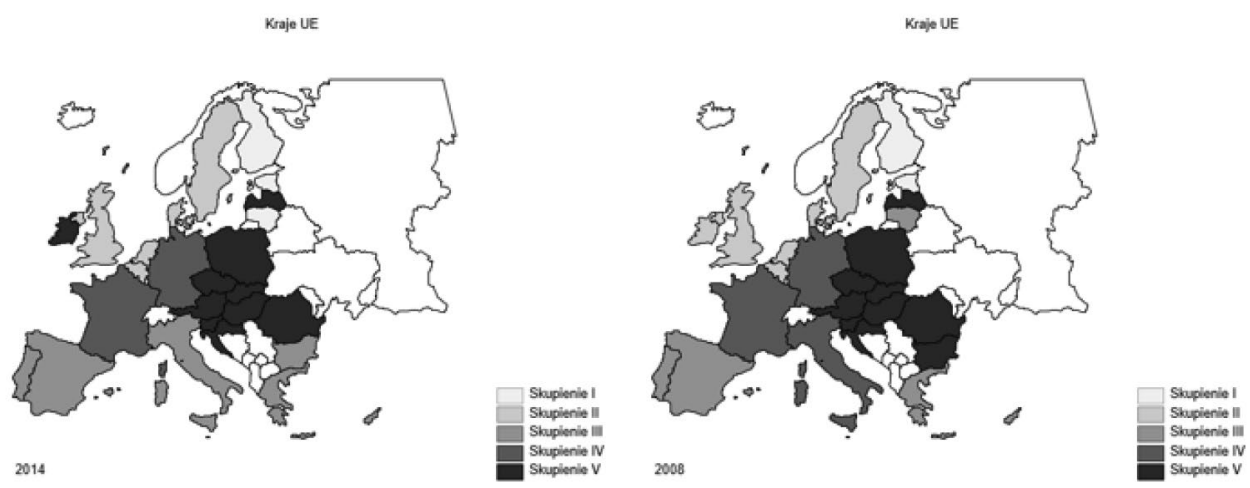

Rys. 1. Skupienia krajów UE pod względem podobieństwa w rozwoju sektora bankowo-kredytowego w latach 2014 i 2008

Źródło: opracowanie własne.

\section{Ranking krajów UE pod względem poziomu rozwoju sektora bankowo-kredytowego}

Do wyznaczenia rankingu rozwoju sektora bankowo-kredytowego w krajach Unii Europejskiej zastosowano miernik syntetyczny rozwoju:

$$
M 1_{i}=\frac{G D M 1_{i}^{-}}{\left(G D M 1_{i}^{-}+G D M 1_{i}^{+}\right)},
$$


będący miernikiem syntetycznym typu TOPSIS z odległościami GDM1 od dolnego oraz górnego bieguna rozwoju (w wariancie $\mathrm{z}$ jednakowymi wagami) oraz analogiczny miernik $M 2_{i}-\mathrm{w}$ wariancie $\mathrm{z}$ wagami zróżnicowanymi. Wagi dla $j$-tej zmiennej diagnostycznej uzależniono od wartości współczynników zmienności $V_{s j}$ i obliczono ze wzoru:

$$
\omega_{j}=\frac{V_{s j}}{\sum_{j} V_{s j}}
$$

(im bardziej zmienna różnicuje badane kraje, tym większą posiada wagę). Przyjęto, że zmienne diagnostyczne: $\mathrm{X}_{3}$ i $\mathrm{X}_{9}$ - będą destymulantami, zaś pozostałe zmienne to stymulanty. Ostateczne wartości miernika syntetycznego $M_{i}$ wyznaczono jako średnią z wartości obu mierników cząstkowych i w oparciu o jego wartości wyznaczono ostateczne rankingi (zob. tabela 3).

Tabela 3. Ranking krajów UE pod względem poziomu rozwoju sektora bankowo-kredytowego w 2014 i 2008 roku

\begin{tabular}{|c|c|c|c|c|c|c|c|c|c|}
\hline \multirow[t]{2}{*}{ Kraj } & \multicolumn{2}{|c|}{$\begin{array}{c}\text { Miernik } \\
\text { syntetyczny } \\
M_{i}\end{array}$} & \multicolumn{2}{|c|}{ Ranking } & \multirow[t]{2}{*}{ Kraj } & \multicolumn{2}{|c|}{$\begin{array}{c}\text { Miernik } \\
\text { syntetyczny } \\
M_{i}\end{array}$} & \multicolumn{2}{|c|}{ Ranking } \\
\hline & 2014 & 2008 & 2014 & 2008 & & 2014 & 2008 & 2014 & 2008 \\
\hline Wielka Brytania & 0,814 & 0,798 & 1 & 1 & Polska & 0,397 & 0,294 & 15 & 19 \\
\hline Luksemburg & 0,721 & 0,735 & 2 & 2 & Czechy & 0,366 & 0,225 & 16 & 26 \\
\hline Hiszpania & 0,684 & 0,687 & 3 & 3 & Chorwacja & 0,348 & 0,345 & 17 & 18 \\
\hline Francja & 0,637 & 0,541 & 4 & 5 & Bułgaria & 0,347 & 0,396 & 18 & 13 \\
\hline Włochy & 0,558 & 0,433 & 5 & 9 & Słowacja & 0,328 & 0,253 & 19 & 24 \\
\hline Niemcy & 0,546 & 0,518 & 6 & 7 & Litwa & 0,328 & 0,361 & 20 & 16 \\
\hline Holandia & 0,539 & 0,383 & 7 & 14 & Grecja & 0,326 & 0,291 & 21 & 20 \\
\hline Szwecja & 0,533 & 0,430 & 8 & 10 & Rumunia & 0,324 & 0,279 & 22 & 21 \\
\hline Malta & 0,512 & 0,439 & 9 & 8 & Estonia & 0,322 & 0,223 & 23 & 27 \\
\hline Belgia & 0,504 & 0,404 & 10 & 11 & Łotwa & 0,319 & 0,271 & 24 & 22 \\
\hline Portugalia & 0,487 & 0,368 & 11 & 15 & Irlandia & 0,317 & 0,520 & 25 & 6 \\
\hline Cypr & 0,478 & 0,563 & 12 & 4 & Słowenia & 0,284 & 0,231 & 26 & 25 \\
\hline Austria & 0,417 & 0,356 & 13 & 17 & Węgry & 0,223 & 0,266 & 27 & 23 \\
\hline Dania & 0,408 & 0,400 & 14 & 12 & Finlandia & 0,218 & 0,209 & 28 & 28 \\
\hline
\end{tabular}

Źródło: opracowanie własne. 


\section{Zakończenie}

Podsumowując wyniki przeprowadzonych badań, można zauważyć kilka interesujących wniosków. Okres kryzysu nie wpłynął znacząco na zmianę struktury skupień krajów podobnych pod względem rozwoju sektora bankowo-kredytowego. Polska plasuje się raczej w środku stawki krajów UE w wyznaczonych rankingach rozwoju badanego sektora. W roku 2008 zajmowała 19 pozycję, zaś w 2014 odnotowała (co bardzo cieszy) awans na 15 pozycję. Świadczy to o dość dobrej odporności systemu bankowego w Polsce na pojawiające się kryzysy finansowe. Najlepszym, stabilnym, wysokim poziomem rozwoju systemu bankowo-kredytowego charakteryzują się takie kraje, jak: Wielka Brytania, Luksemburg, Hiszpania, Francja, Niemcy Włochy oraz Holandia. Najgorzej w rozwoju wypadają: Finlandia, Węgry, Słowenia. Kraje Europy Środkowo-Wschodniej wypadają słabo w rankingach rozwoju. Najwyżej są Polska i Czechy na 15 i 16 pozycji w 2014 r. Najgorszą pozycję, 27, w 2014 roku zajmowały Węgry. Na niektóre kraje, takie jak: Cypr i Irlandia, kryzys finansowy i jego konsekwencje wywarły niekorzystny wpływ. Cypr przed kryzysem w 2008 r. zajmował wysoką, 4 pozycję w rankingu, zaś w 2014 spadł na 12 pozycję. Jeszcze znaczniejszy spadek odnotowała Irlandia, która z pozycji 6 w 2008 r. spadła na 25 w 2014 r. Spowodowane jest to kryzysem, głównie dużym spadkiem wartości udzielanych kredytów przez instytucje kredytowe tych krajów, dużym wzrostem odsetka złych kredytów oraz znacznym spadkiem zatrudnienia w sektorze bankowo-kredytowym.

\section{Literatura}

European Banking Federation, 2015, European banking sector. Facts and Figures, http://www.ebf-fbe. eu/publications/statistics/ (10.06.2016).

Financial Soundness Indicators database, http://data.imf.org/?sk=9F855EAE-C765-405E-9C9AA9DC2C1FEE47\&ss=1390030109571 (10.06.2016).

Girolami M., 2002, Mercer kernel-based clustering in feature space, IEEE Transactions on Neural Networks, vol. 13, no. 3, s. 780-784.

Grabiński T., Wydymus S., Zeliaś A., 1989, Metody taksonomii numerycznej w modelowaniu zjawisk społeczno-gospodarczych, PWN, Warszawa.

Lepczyński B., Penczar M., 2014, Zmiany w pozycji polskiego sektora bankowego na europejskim rynku depozytowo-kredytowym, [w:] Zarzecki D. (red.), Zarządzanie finansami w przedsiębiorstwach i jednostkach samorzadu terytorialnego, Wydawnictwo Uniwersytetu Szczecińskiego, Szczecin, s. 523-540.

Statistical Data Warehouse database, http://sdw.ecb.europa.eu/ (10.06.2016).

Stefański M. 2010, Sektory bankowe nowych państw członkowskich Unii Europejskiej, Współczesna Ekonomia, nr 1, s. 21-46.

Walesiak M., 2016, Uogólniona miara odległości GDMw statystycznej analizie wielowymiarowej z wykorzystaniem programu $R$, Wydawnictwo Uniwersytetu Ekonomicznego we Wrocławiu, Wrocław.

Walesiak M., Dudek A., 2009, Odległość GDM dla danych porządkowych a klasyfikacja spektralna, Prace Naukowe Uniwersytetu Ekonomicznego we Wrocławiu, nr 84, s. 9-19. 